\title{
Inbreeding and developmental stability in a laboratory strain of the bank vole Clethrionomys glareolus
}

\author{
Vladimir M. ZAKHAROV and Michal D. SIKORSKI
}

\begin{abstract}
Zakharov V. M. and Sikorski M. D. 1997. Inbreeding and developmental stability in a laboratory strain of the bank vole Clethrionomys glareolus. [In: Developmental homeostasis in natural populations of mammals: phenetic approach. V. M. Zakharov and A. V. Yablokov, eds]. Acta Theriologica, Suppl. 4: 73-78.
\end{abstract}

Developmental stability and phenotypic diversity of the bank vole Clethrionomys glareolus Schreber, 1780 were tested in a group of founders collected from natural population in Białowieża National Park (Poland) and in a sample taken from the 20th generation of a laboratory mass-cross strain derived from these founders. Fluctuating asymmetry of 28 skull characters such as the number of foramina were used as a measure of developmental stability. Variance of the foramina on the left and right sides of the skull for the same characters was used as a measure of phenotypic diversity. The data obtained indicate a developmental stability decrease and phenotypic diversity increase as a result of inbreeding during 20 generations in the laboratory.

N. K. Koltzov Institute of Developmental Biology, Russian Academy of Sciences, Vavilov Str. 26, Moscow 117808, Russia (VMZ); Mammal Research Institute Polish Academy of Sciences, 17-230 Białowieża, Poland (MDS)

Key words: Clethrionomys glareolus, fluctuating asymmetry, developmental stability, phenotypic diversity, inbreeding

\section{Introduction}

The condition of the laboratory strains has both a fundamental and applied interest to detect possible changes in the health and future prospects of their survival in captivity. Genetic diversity decreases, resulting from a limited number of founders, and inbreeding are the main causes of alteration in a laboratory strain. A sensitive index of an organism's condition is developmental stability. The simplest way to test developmental stability level is by fluctuating asymmetry of morphological characters. Developmental stability decrease under inbreeding has been reported in various studies dealing with different animals (Kat 1982, Leary et al. 1983, 1984, 1992, Wayne et al. 1986, Modi et al. 1987, Zakharov et al. 1995).

The aim of this study was to examine changes in developmental stability of a strain of the bank vole Clethrionomys glareolus Schreber, 1780 kept during 20 generations of the laboratory maintenance in the Mammal Research Institute. 


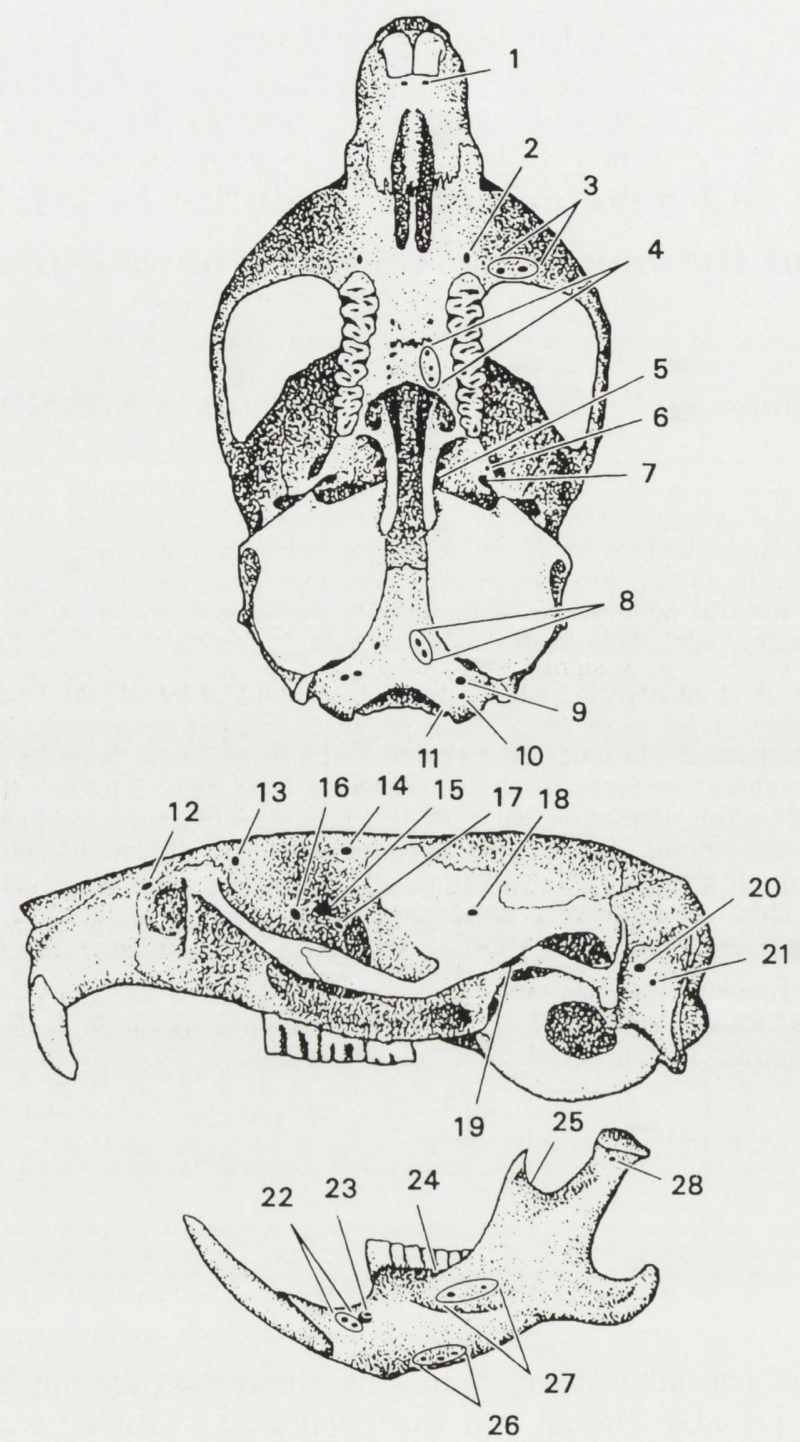

Fig. 1. Cranial characters, as a number of foramina (1-28), examined in the bank vole Clethrionomys glareolus. 1 -foramen praemaxillaris ventralis, 2 - foramen diastemae, 3 - foramen basis processus zygomaticum, 4 - foramen palatinae, 5 - foramen pterygoideum, 6 - foramen ovale accessorius, 7 foramen ovale accessorius anterior, 8 -foramen basioccipitale, 9 -foramen hypoglossum, 10 - foramen hypoglossum accessorius internus, 11 - foramen hypoglossum intracondylaris, 12 - foramen suprainfraorbitalis, 13 - foramen supraorbitalis anterior, 14 - foramen supraorbitalis posterior, 15 - foramen ethmoideum, 16 - foramen ethmoideum accessory anterior, 17 -foramen ethmoideum accessory posterior, 18 - foramen squamosum, 19 - foramen postglenoidale, 20 - foramen mastoideum, 21 foramen mastoideum accessorius, 22 -foramen mentale accessorius, 23 - foramen mentale accessorius internus, 24 - foramen mandibularis pars alveolaris, 25 - foramen mandibularis pars alveolaris posterior, 26 - foramen basis mandibularis, 27 - foramen mandibularis masseterica, 28 - foramen processus condylaris. 


\section{Material and methods}

Skulls from the Mammal Research Institute, Polish Academy of Sciences (Białowieża, Poland) were used. We compared two samples of the bank vole (38 young specimens each): the founders collected from the natural population in Białowieża National Park ("generation 0") and a sample taken from the 20th generation of the laboratory strain derived from them ("generation 20").

Fluctuating asymmetry of 28 skull characters was examined to measure developmental stability (Fig. 1). Mean number of foramina was equal in both left and right sides of the skull for 5 characters and slightly higher on the left side in 9 characters in "generation 0 ", while in "generation 20 " it was equal for 3 characters and higher on the left side for 10 characters, with significant difference in a single character in each direction. As the direction for difference varied for the same characters in different samples we conclude that these differences appeared by chance only. As we did not find indications of either directional asymmetry or antisymmetry in variation of these characters, the difference in foramina numbers on the left and right sides of the skull (l-r) was considered as fluctuating asymmetry (Van Valen 1962, Soulé 1967, Zakharov 1987, 1989).

All these characters as well as their asymmetries proved to be uncorrelated with each other in both samples studied. The coefficient of correlation in all possible paired comparisons (378) of the characters reached the statistically significant level in 5 cases for $(l+r)$ and in 3 cases for (l-r) in "generation 0"; and in 3 cases for $(1+r)$ as well as for $(1-r)$ in "generation 20", significant correlation values were revealed in each sample for different characters. These single statistically significant differences can be regarded as type I statistical error (Vrijenhoek and Lerman 1982, Zakharov 1987, 1989). Absence of sex differences in analyzed parameters allowed us to compare the total samples.

Variance for $(1-r)$ and for $(1-r) /(1+r)$ were used to measure fluctuating asymmetry (Palmer and Strobeck 1986, Zakharov 1987). We used mean number of asymmetrical characters per individual as an integrated measure of developmental stability (Leary et al. 1985, Zakharov 1989). Total phenotype diversity was measured by variance for $(l+r)$. The non-parametric sign-test was used for the intersample comparison of variances for the whole set of characters. An $F$-test was used for pairwise comparisons of the variances and Student's $t$-test for the intergroup comparison of the mean number of asymmetrical characters per individual (Sokal and Rohlf 1981).

\section{Results}

Variance for $(l-r)$ was used as the main measure of developmental stability for separate characters. It was higher in "generation 20 " than in "generation 0 " in a majority of the characters under study: for 24 of 28 characters with equal values for one character $(p<0.01$, sign-test; Table 1$)$. This variance was significantly higher $(p<0.05)$ in "generation 20 " for 13 characters and in "generation 0 " for only 1 character $(p<0.01$, sign-test).

Variance of $(l-r) /(1+r)$ showed the same pattern for intersample difference: it was higher in "generation 20" for 19 characters with equal level in both sample for 3 characters $(p<0.01$, sign-test); it was significantly higher $(p<0.05)$ in "generation 20" for 8 characters and in "generation 0 " for only 1 character $(p<0.01)$.

The mean number of asymmetrical characters was taken as an integrated measure of developmental stability. It revealed the same tendency being significantly higher $(p<0.001)$ in "generation 20 " $(13.42 \pm 0.44)$ than in "generation 0 " $(9.26 \pm 0.36)$. Total phenotypic diversity measured by variance for $(l+r)$ proved to 
Table 1 . The values of the total phenotypic variance [variance for $(1+r)]$ and fluctuating asynmetry [variance for (l-r)] for 28 characters of skull morphology (Fig. 1) in two samples ("generation 0" and "generation 20") of the bank vole Clethrionomys glareolus. Statistical significance (Student's $t$-test) of the differences between two samples is presented as $p$. The higher value in a paired data conpared is underlined.

\begin{tabular}{|c|c|c|c|c|c|c|}
\hline \multirow{2}{*}{$\begin{array}{l}\text { Number of } \\
\text { character }\end{array}$} & \multicolumn{2}{|c|}{ Variance $(l+r)$} & \multirow{2}{*}{$p$} & \multicolumn{2}{|c|}{ Variance $(1-r)$} & \multirow{2}{*}{$p$} \\
\hline & "generation $0 "$ & "generation 20 " & & "generation 0" & "generation 20 " & \\
\hline 1 & $\underline{0.92}$ & 0.75 & $\mathrm{~ns}$ & 0.22 & $\underline{0.49}$ & $<0.01$ \\
\hline 2 & $\overline{0.98}$ & $\underline{1.10}$ & $\mathrm{~ns}$ & 0.48 & $\underline{0.67}$ & $\mathrm{~ns}$ \\
\hline 3 & 0.65 & 0.71 & ns & 0.77 & 1.04 & $\mathrm{~ns}$ \\
\hline 4 & $\underline{0.77}$ & 0.56 & $\mathrm{~ns}$ & 0.22 & $\underline{0.34}$ & $\mathrm{~ns}$ \\
\hline 5 & 0.73 & $\underline{0.84}$ & $\mathrm{~ns}$ & 0.24 & 0.35 & $\mathrm{~ns}$ \\
\hline 6 & 1.45 & $\underline{1.67}$ & ns & 0.35 & $\underline{0.79}$ & $<0.01$ \\
\hline 7 & 0.12 & 0.25 & $<0.05$ & 0.13 & 0.05 & $<0.01$ \\
\hline 8 & $\underline{6.74}$ & 3.62 & $<0.05$ & 0.85 & $\underline{2.48}$ & $<0.01$ \\
\hline 9 & 2.92 & 1.97 & ns & 1.19 & 2.45 & $<0.05$ \\
\hline 10 & 0.34 & $\underline{0.69}$ & $<0.05$ & 0.23 & 0.34 & ns \\
\hline 11 & $\underline{1.05}$ & 0.89 & ns & 0.92 & $\underline{1.10}$ & ns \\
\hline 12 & 0.05 & 0.07 & $\mathrm{~ns}$ & 0.05 & 0.07 & ns \\
\hline 13 & 0.36 & $\underline{0.46}$ & $\mathrm{~ns}$ & $\underline{0.41}$ & 0.39 & ns \\
\hline 14 & 0.84 & 1.14 & $\mathrm{~ns}$ & 0.56 & 0.68 & ns \\
\hline 15 & $\underline{0.17}$ & 0.10 & $\mathrm{~ns}$ & 0.07 & $\underline{0.10}$ & ns \\
\hline 16 & 1.54 & 1.84 & ns & 0.17 & 0.95 & $<0.01$ \\
\hline 17 & 1.36 & $\underline{3.11}$ & $<0.01$ & 0.62 & $\underline{1.73}$ & $<0.01$ \\
\hline 18 & 0.57 & $\underline{1.20}$ & $<0.05$ & 0.30 & $\underline{1.59}$ & $<0.01$ \\
\hline 19 & $\underline{0.93}$ & 0.87 & ns & 0.30 & 0.39 & ns \\
\hline 20 & 0.47 & $\underline{0.88}$ & $<0.05$ & 0.22 & $\underline{0.53}$ & $<0.01$ \\
\hline 21 & 0.03 & 0.15 & $<0.01$ & 0.03 & 0.15 & $<0.01$ \\
\hline 22 & 0.05 & $\underline{0.13}$ & $<0.01$ & $\underline{0.05}$ & 0.03 & $\mathrm{~ns}$ \\
\hline 23 & 2.61 & 2.06 & ns & 1.32 & 2.18 & $\mathrm{~ns}$ \\
\hline 24 & $\underline{4.46}$ & 3.45 & ns & 1.38 & $\underline{2.74}$ & $<0.05$ \\
\hline 25 & 0.19 & 0.36 & $<0.05$ & 0.10 & 0.43 & $<0.01$ \\
\hline 26 & 1.95 & 2.83 & ns & 1.11 & 1.11 & $\mathrm{~ns}$ \\
\hline 27 & 2.17 & $\underline{5.13}$ & $<0.01$ & 1.05 & $\underline{2.12}$ & $<0.05$ \\
\hline 28 & 7.99 & 8.58 & ns & 1.57 & 4.47 & $<0.01$ \\
\hline
\end{tabular}

be also higher in "generation 20" than in "generation 0 " (Table 1): the variance was higher for 19 characters in "generation 20 " $(p<0.05$, sign-test). In 10 characters showing statistically significant differences $(p<0.05)$ the variance was higher for 9 characters in "generation 20 " $(p<0.01)$. For 15 of 19 characters an increase of variance for $(l+r)$ was accompanied by an increase in variance for $(l-r)$ $(p<0.01$, sign-test). The proportion of variance for $(l-r)$ in variance for $(l+r)$, measured by their ratio, proved to be higher in "generation 20 " in 18 characters with an equal ratio in both samples for 2 characters $(p<0.05)$. 


\section{Discussion}

Decrease in heterozygosity is commonly considered as one of the main cause of deterioration of developmental stability. In many cases decline in developmental stability level is actually observed under inbreeding (Leary et al. 1992, Zakharov et al. 1995), but this is not universal (Fowler and Whitlock 1994, Strunnikov 1994). Developmental stability seems to depend on particular alleles with adverse effect on an organism's condition rather then on average heterozygosity as such. This could be the explanation for these contradictory results. Whether decline in average heterozygosity is accompanied by transformation of these particular loci in a homozygous state or not will determine the presence or absence of developmental stability disturbance under the inbreeding impact (Zakharov 1987, 1989).

In this study we examined whether there was any decrease in developmental stability during 20 generations of laboratory breeding in a strain derived from the natural population. The data revealed a decline in developmental stability in "generation 20" compared with the founders, "generation 0 " for different indices. Increased homozygosity can be assumed to be the main reason for the fall in developmental stability. While heterozygosity has not been determined in the samples compared, there is some evidence for this assumption. In particular, there has been a marked decrease heterozygosity in laboratory strain compared from the nature population in an electrophoretic study of esterases (Wójcik and Fedyk 1984).

An increase of total phenotypic diversity is another evidence of change in condition under inbreeding (Handford 1980, McAndrew et al. 1982). The probable reason for such phenotypic increase in variability with genotypic decrease is the high level of developmental noise following deterioration in developmental stability (Robertson and Reeve 1952, Rasmuson 1960, King 1961). The results presented here show a developmental stability decrease during 20 generations of laboratory maintenance. A reduction in genotype diversity as a result of the founder effect, genetic drift or inbreeding may lead to changes in an organism's condition.

Acknowledgements: The work was conducted in the frames of a bilateral agreement between the Russian and Polish Academies of Sciences. We are very grateful to Prof Z. Pucek for his help at each step of this work. We also appreciate assistance of S. Buszko in using collection and stimulating discussion of the results with scientific Staff of the Mammal Research Institute PAS in Białowieża. We are very grateful to three anonymous referees provided very helpful comments and corrections of English.

\section{References}

Fowler K. and Whitlock M. C. 1994. Fluctuating asymmetry does not increase with moderate inbreeding in Drosophila melanogaster. Heredity 73: 373-376.

Handford P. 1980. Heterozygosity at enzyme loci and morphological variation. Nature 286: 261-262.

Kat P. W. 1982. The relationship between heterozygosity for enzyme loci and developmental homeostasis in peripheral populations of aquatic bivalves (Unionidae). American Naturalist 119: 824-832. 
King J. C. 1961. Inbreeding, heterosis and information theory. American Naturalist 95: 345-364.

Leary R. F., Allendorf F. W. and Knudsen K. L. 1983. Developmental stability and enzyme heterozygosity in rainbow trout. Nature 301: 71-72.

Leary R. F., Allendorf F. W. and Knudsen K. L. 1984. Superior developmental stability of heterozygotes at enzyme loci in salmonid fishes. American Naturalist 124: 540-551.

Leary R. F., Allendorf F. W. and Knudsen K. L. 1985. Developmental instability as an indicator of reduced genetic variation in hatchery trout. Transactions of American Fisheries Society 114: 230-235.

Leary R. F., Allendorf F. W. and Knudsen K. L. 1992. Genetic, environmental, and develcpmental causes of meristic variation in rainbow trout. Acta Zoologica Fennica 191: 79-95.

McAndrew B. J., Ward R. D. and Beardmore J. A. 1982. Lack of relationship between morphological variance and enzyme heterozygosity in the plaice, Pleuronectes platessa. Heredity 48: 117-125.

Modi W. S., Wyne R. K. and O'Brien S. J. 1987. Analysis of fluctuating asymmetry in cheetahs. Evolution 41: 227-228.

Palmer R. A. and Strobeck C. 1986. Fluctuating asymmetry: measurement, analysis, patterns. Annual Review in Ecology and Systematic 17: 391-421.

Rasmuson M. 1960. Frequency of morphological deviants as a criterion of developmental stability. Hereditas 46: 511-536.

Robertson F. W. and Reeve E. C. R. 1952. Heterozygosity, environmental variation and heterosis. Nature 170: 286-296.

Sokal R. R. and Rohlf J. F. 1981 Biometry. Freeman, San-Francisco: 1-859.

Soulé M. E. 1967. Phenetics of natural populations. II. Asymmetry and evolution in a lizard. American Naturalist 101: 141-160.

Strunnikov V. A. 1994. [The nature of heterosis and new methods of its increase.] Nauka, Moskva: 1-108. [In Russian]

Van Valen L. 1962. A study of fluctuating asymmetry. Evolution 16: 125-142.

Vrijenhoek R. C. and Lerman S. 1982. Heterozigosity and developmental stability under serual and asexual breeding systems. Evolution 36: 768-776.

Wayne R. K., Modi W. S. and O’Brien S. J. 1986. Morphological variability and asymmetry in the cheetah (Acinonyx jubatus), a genetically uniform species. Evolution 40: 78-85.

Wójcik A. M. and Fedyk S. 1984. Breeding parameters in the bank vole of different esterase phenotypes. Acta Theriologica 29: 305-316.

Zakharov V. M. 1987. [Animal asymmetry: population-phenogenetic approach.] Nauka, Moskva: 1-216. [In Russian]

Zakharov V. M. 1989. Future prospects for population phenogenetics. Soviet Science Reviews, Section F 4 (3): 1-79.

Zakharov V. M., Shchepotkin D. V. and Strunnikov V. A. 1995. [The heterozygosity and temperature impact on the developmental stability of silkworm Bombix mori.] Doklady Akademii Nauk 340 (3): 430-432. [In Russian]

Received 7 December 1995, revised 10 October 1996, accepted 10 April 1997. 